\title{
ENERGY AND EXERGY THERMODYNAMIC ANALYSIS OF A TWO-STAGE COMPRESSION REFRIGERATION SYSTEM INTEGRATED WITH AN ABSORPTION SYSTEM $\left(\mathrm{NH}_{3}+\mathrm{H}_{2} \mathrm{O}\right)$
}

\begin{abstract}
G. A. Corrêa ${ }^{a}$,
J.A. Souza ${ }^{\mathrm{a}, *}$,

C. Prentice-Hernández and L. A. O. Rocha

${ }^{a}$ FURG - Universidade Federal do Rio Grande Dep. de Física, Av. Itália, km 8, 96201-900

Campus Carreiros, Rio Grande, RS, Brasil ${ }^{b}$ FURG - Universidade Federal do Rio Grande Dep. de Química, Rua Eng. Alfredo Huch, 475 96201-900, Campus Cidade, Rio Grande, RS Brasil

${ }^{*}$ Corresponding author,e-mail: jasouza@furg.br

\section{ABSTRACT}

This work proposes an energetic and exergetic thermodynamic analysis of two refrigeration systems: one is a conventional two stages cooling system by steam compression of ammonia and the other is named integrated refrigeration system. The conventional system, used as reference, is largely employed in cooling fish industry. The integrated refrigeration system is similar to the conventional one, although it uses in the intermediate cooling, between the stages of high and low pressure, cold water in closed circuit. The cold water is supplied by ammonia-water absorption system integrated to the conventional compression system. The calorific energy supplied is obtained from waste exceeding of the fish meal production thus the energy delivered to the integrated refrigeration system is considered of zero cost. Numeric simulation is employed to compare the behavior of both systems. The results obtained in this comparison show that the integrated refrigeration system operates with a reduction of up to $19.73 \%$ in COP. However, the integrated refrigeration system presented an increase of up to $25.57 \%$ in exergetic efficiency and $33.09 \%$ in frigorific capacity in relation to the conventional system. These results, added to the decrease of operational cost which will be quantified in a further study, will make very attractive the use of the integrated refrigeration system.
\end{abstract}

Keywords: compression-absorption system; ammonia-water; exergy.

\section{NOMENCLATURE}

\begin{tabular}{|c|c|}
\hline ARS & Absorption refrigeration system \\
\hline $\mathrm{COP}$ & Coefficient of performance \\
\hline CRS & Compression refrigeration system \\
\hline CRSmod & CRS modified system \\
\hline e & Specific exergy $\left(\mathrm{kJ} . \mathrm{kg}^{-1}\right)$ \\
\hline $\mathrm{E}$ & Exergy $\left(\mathrm{kJ} . \mathrm{s}^{-1}\right)$ \\
\hline $\mathrm{EV}$ & Expansion valve \\
\hline $\mathrm{h}$ & Specific enthalpy $\left(\mathrm{kJ} . \mathrm{kg}^{-1}\right)$ \\
\hline IRS & Integrated refrigeration system \\
\hline$\dot{\mathrm{m}}$ & Mass flow rate $\left(\mathrm{kg} . \mathrm{s}^{-1}\right)$ \\
\hline $\mathrm{p}$ & Pressure $(\mathrm{kPa})$ \\
\hline$\dot{\mathrm{Q}}$ & Rate of heat transfer $\left(\mathrm{kJ} . \mathrm{s}^{-1}\right)$ \\
\hline $\mathrm{s}$ & Specific entropy $\left(\mathrm{kJ} \cdot \mathrm{kg}^{-1} \cdot \mathrm{K}^{-1}\right)$ \\
\hline $\mathrm{T}$ & Temperature $\left(\mathrm{K}\right.$ or $\left.{ }^{\circ} \mathrm{C}\right)$ \\
\hline $\mathrm{v}$ & Specific volume $\left(\mathrm{m}^{3} \mathrm{~kg}^{-1}\right)$ \\
\hline$\dot{\forall}$ & Volume flow rate $\left(\mathrm{m}^{3} \cdot \mathrm{s}^{-1}\right)$ \\
\hline W & Power input $\left(\mathrm{kJ} . \mathrm{s}^{-1}\right)$ \\
\hline$\dot{\mathrm{We}}$ & Electric power \\
\hline $\mathrm{X}$ & Mass fraction ammonia-water \\
\hline
\end{tabular}

Greek symbols

$\begin{array}{ll}\Delta & \text { Difference } \\ \varepsilon & \text { Exergetic efficiency } \\ \eta_{\mathrm{c}} & \text { Compressor efficiency } \\ \eta_{\mathrm{b}} & \text { Pump efficiency }\end{array}$

\section{Subscripts}

$\begin{array}{ll}0 & \text { Ambient } \\ \mathrm{C} & \text { Condenser } \\ \mathrm{E} & \text { Evaporator } \\ \mathrm{f} & \text { Fraction solution } \\ \mathrm{G} & \text { Generator } \\ \mathrm{i} & \text { Interstage } \\ \mathrm{L} & \text { Liquid phase } \\ \mathrm{s} & \text { Strong solution } \\ \text { suCtion } & \text { Regarding suction } \\ \mathrm{V} & \text { Vapor phase } \\ \mathrm{VC} & \text { Control volumes } \\ \mathrm{W} & \text { Weak solution } \\ 1,2, \ldots & \text { Initial and final state; control volume inlet } \\ & \text { and exit }\end{array}$

\section{Superscripts}

$\begin{array}{ll}0 & \text { Standard state value } \\ \mathrm{n} & \text { Polytropic coefficient } \\ \mathrm{CH} & \text { Chemical component } \\ \mathrm{PH} & \text { Physical component }\end{array}$

\section{INTRODUCTION}

Energetic and exergetic thermodynamic analysis have been widely applied to analyze the performance of cooling plants. Kotas (1985) described the 
occurrence of energetic losses in individual processes and its quantification in detailed analysis of heat and mass transfer. Pátek and Komflar (1995) presented a set of equations which describe the proprieties of vapor-liquid balance for ammonia-water. Such equations were submitted to comparison with the data reported in the literature, presenting, without need for adjustments, good results, and thus, enabling to contribute with the analysis of these systems. Bejan et al. (1996) studied the application of the first and second law of thermodynamics and, in particular, the concept of exergy in the analysis of thermal system and in the qualitative evaluation of efficiencies, as well as the principles of exergy and its application in analysis of thermal systems and thermo-economy. Nikolaids and Probert (1998) used the exergy method to investigate a refrigeration system by compression in two stages. The temperature of condensation ranged from $298 \mathrm{~K}$ to $308 \mathrm{~K}$, and the temperature of evaporation ranged from $228 \mathrm{~K}$ to $238 \mathrm{~K}$. It was determined an irreversibility rate of the plant taking into account the effects of changes in temperature in the condenser and in the evaporator. Göktun (1999) studied the performance of an irreversible heat engine-driven which combines a vapor compression (VCR) and absorption refrigerator (AR), where the condensation of the AR unit discharges heat to the evaporator of the VCR unit. The heat of the condenser of the VCR is, then, delivered to the external medium for its heating. Kaynakli and Kilic (2007) presented a detailed analysis of an absorption cooling cycle operating with lithium bromate/water. They also analyzed the influence of operational temperatures, coefficient of performance (COP), effectivity of the interchanger of heat and heat removed from the components of this cycle. The study of Kairouani and Nehdi (2006) aimed to develop a new cycle of refrigeration, where the geothermal energy is applied in a simple vapor compression system, and to discuss the thermodynamic analysis of the cycle and the practical viability of its development. This refrigeration system in cascade consists of a vapor compression system combined with an absorption system. Cabello et al. (2007) analyzed the variation of parameters in a plant of vapor compression of a single stage. These included changes in temperature of condensation and evaporation and the degree of overheating in the suction of the compressor.

On the other hand, the measure taken in general by the frigorific industry is the compression by stages, when the difference is very high between the temperature of hot and cold sources of the cooling cycle. This allows, through an intermediate cooling, to reduce the effort of compression and to have as a result an increase in the frigorific performance of the plant (Ashrae, 1994). This procedure occurs, in general, by injection of a liquid between the stages, where part of the refrigerant fluid, which could be used for increasing the frigorific capacity, is applied to cool the mass flow rate discharged by the compressor in the first stage.

The aim of this study is to carry out an energetic and exergetic analysis to propose a change in this usual procedure: applying an system of integrated absorption to the compression refrigeration system (CRS), for intermediate cooling, taking up the totality of refrigerant fluid in course and increasing the frigorific capacity of refrigeration

For the compression refrigeration system (CRS) and for the integrated refrigeration system (IRS) were studied the effects of evaporation temperature $\left(T_{E}\right)$, condensation temperature $\left(T_{C}\right)$, intermediate pressure $\left(\mathrm{P}_{\mathrm{i}}\right)$, degree of overheating in the temperature of suction $\left(\mathrm{T}_{\text {SUCTION }}\right)$, in the power of the compressors ( $\dot{\mathrm{W}})$, in the heat transfer rates, $(\dot{Q})$, in the coefficient of performance (COP) and in the exergetic efficiency $(\varepsilon)$.

\section{Conventional and Integrated Systems of Refrigeration.}

Figure 1 shows the compression refrigeration system (CRS) in use in the plant with temperatures of the evaporators of low and intermediate pressure, respectively $\mathrm{T}_{\mathrm{E} 1}=-40^{\circ} \mathrm{C}$ and $\mathrm{T}_{\mathrm{E} 2}=-10^{\circ} \mathrm{C}$, and temperature of condensation $\mathrm{T}_{\mathrm{C}}=35^{\circ} \mathrm{C}$.

The evolution of ammonia flowing in CRS starts in the state of overheated vapor, when it leaves the compressor of high (state 13). Ammonia is, then, liquefied in the condenser, turning into a saturated liquid (state 14); next, this flowing divides into three streams. The first $\dot{\mathrm{m}}_{\mathrm{a} 1}$ crosses a expansion valve, where it is expanded isenthalpically, submitted to pressure corresponding to the lowest temperature $\mathrm{T}_{\mathrm{E} 1}$ (state 16). This stream runs through the intercooler, and, as it flows down the evaporator 1 absorbs heat, making it a saturated vapor (state 17 ) and, following, it goes by compressor 1 leaving as overheated vapor (state 18). The second stream $\dot{\mathrm{m}}_{\mathrm{a} 2}$ aims to inject liquid ammonia to cool partially the overheated vapor (state 18) in the exit compressor 1 , this is due to the reduction of temperature of ammonia corresponding to the intermediate pressure (state 25), obtained through isenthalpic expansion in a expansion valve. As a result, there is a mixture $\dot{\mathrm{m}}_{\mathrm{a} 1}+\dot{\mathrm{m}}_{\mathrm{a} 2}$ overheated (state 22). The third stream, $\dot{\mathrm{m}}_{\mathrm{a} 3}$ by crossing another expansion valve, where an isenthalpic expansion occurs, and this one is submitted to an intermediate pressure corresponding to $\mathrm{T}_{\mathrm{E} 2}$ (state 20). Continuing its flow, it runs through the intercooler, and by flowing down in evaporator 2 it absorbs heat, turning into saturated vapor (state 21). Next, it is mixed with $\dot{\mathrm{m}}_{\mathrm{a} 1}+\dot{\mathrm{m}}_{\mathrm{a} 2}$ overheated (state 22) resulting in a mass flow rate $\dot{\mathrm{m}}=\dot{\mathrm{m}}_{\mathrm{a} 1}+\dot{\mathrm{m}}_{\mathrm{a} 2}+\dot{\mathrm{m}}_{\mathrm{a} 3}$ (state 23) which goes through 
the compressor 2 returning to state (13) to complete the cycle.

It is interesting to point out, that overheating increases the specific volume of the fluid aspirated by compressors, increasing, thus, the work of compression. In this refrigeration cycle, the higher the overheating in the suction of compressor 2, the larger is the work. Cooling by injection of liquid $\dot{\mathrm{m}}_{\mathrm{a} 2}$ among the compression stages, it reduces this work, but with a reduction in the frigorific capacity, which could be used by the evaporators, instead.

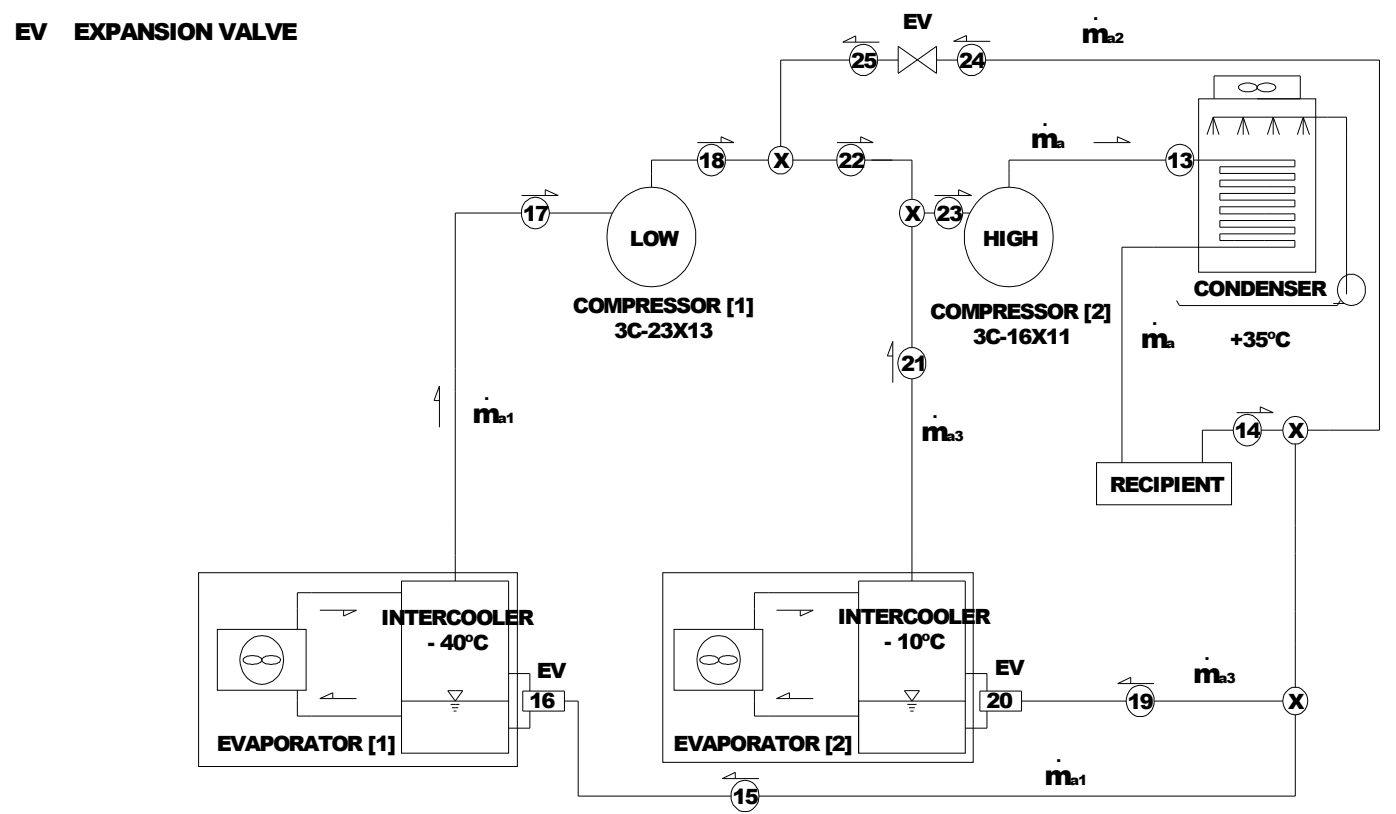

Figure 1. Schematic drawing of CRS used in industry

Figure 2 presents an integrated refrigeration system (IRS). It is similar to the conventional system, although it uses an intermediate cooling as the only difference, cold water in closed circuit, between the stages of high and low pressure. Cold water is kept by a cooling system by absorption water-ammonia, integrated to the conventional system.

IRS is composed of two systems, which can be observed in highlight in Fig. 2, where the temperatures of evaporation, condensation and the assumptions for energy balance of CRSmod are the same used for CRS and for ARS.

It must be observed, yet, that the working fluid in ARS is binary mixture of ammonia and water, and has as its main source of energy the heat transferred to the generator, coming from the thermal waste of fish meal manufacturing produce. ARS is made of the following components: a rectifier, a condenser, an evaporator, an absorber, two expansion valves and the pump of solution ammonia-water.

A brief description of ARS can be initiated by the pump (state 1) where flowing of the binary solution ammonia-water of ARS receives a strong solution from the absorber, $\dot{\mathrm{m}}_{\mathrm{s}}$, liquid to low pressure and has its pressure risen, until the pressure of the heat exchanger (state 2). There, a heat transfer between currents occur, where the strong solution $\dot{\mathrm{m}}_{\mathrm{s}}$ is heated (state 3 ), while the weak solution $\dot{\mathrm{m}}_{\mathrm{w}}$, hot, originally from the generator has its temperature reduced (state 5), as it returns to the absorber (state 6), after its passage through the expansion valve. Liquid solution $\dot{\mathrm{m}}_{\mathrm{s}}$ (state 3 ) enters, then, the refining column, flowing in a countercurrent with the vapor expelled from the generator. This is a process of water vapor removal, with heat transfer and mass in course, until the top of the column (state 8) as a saturated vapor solution $\dot{\mathrm{m}}_{\mathrm{V}}$. To remove the maximum of the water vapor, the solution is cooled, condensating a liquid rich in water, which is drained back into the rectifying column (state 7) as a saturated liquid solution $\dot{\mathrm{m}}_{\mathrm{L}}$. The solution which leaves the rectifier with mass flow rate $\dot{\mathrm{m}}_{\mathrm{f}}$ (state 9) presents a fraction of $0.1 \%$ water. It passes by the condenser, leaving as a saturated liquid (state 10); then, the solution $\dot{\mathrm{m}}_{\mathrm{f}}$ crosses a expansion valve in an isenthalpic expansion, reducing the pressure until it is obtained a temperature of saturation $\mathrm{T}_{\mathrm{E}}$ (state 11). The solution crossing the evaporator, absorbs heat from the water in recirculation with the intermediate cooler of CRSmod, coming out as $\dot{\mathrm{m}}_{\mathrm{f}}$ as saturated vapor of low pressure (state 12). Completing the refrigeration cycle in evolution, the saturated vapor $\dot{\mathrm{m}}_{\mathrm{f}}$ of the evaporator is then absorbed by the liquid solution of the absorber expelling heat for the external medium, and returning to the initial state 1 . 


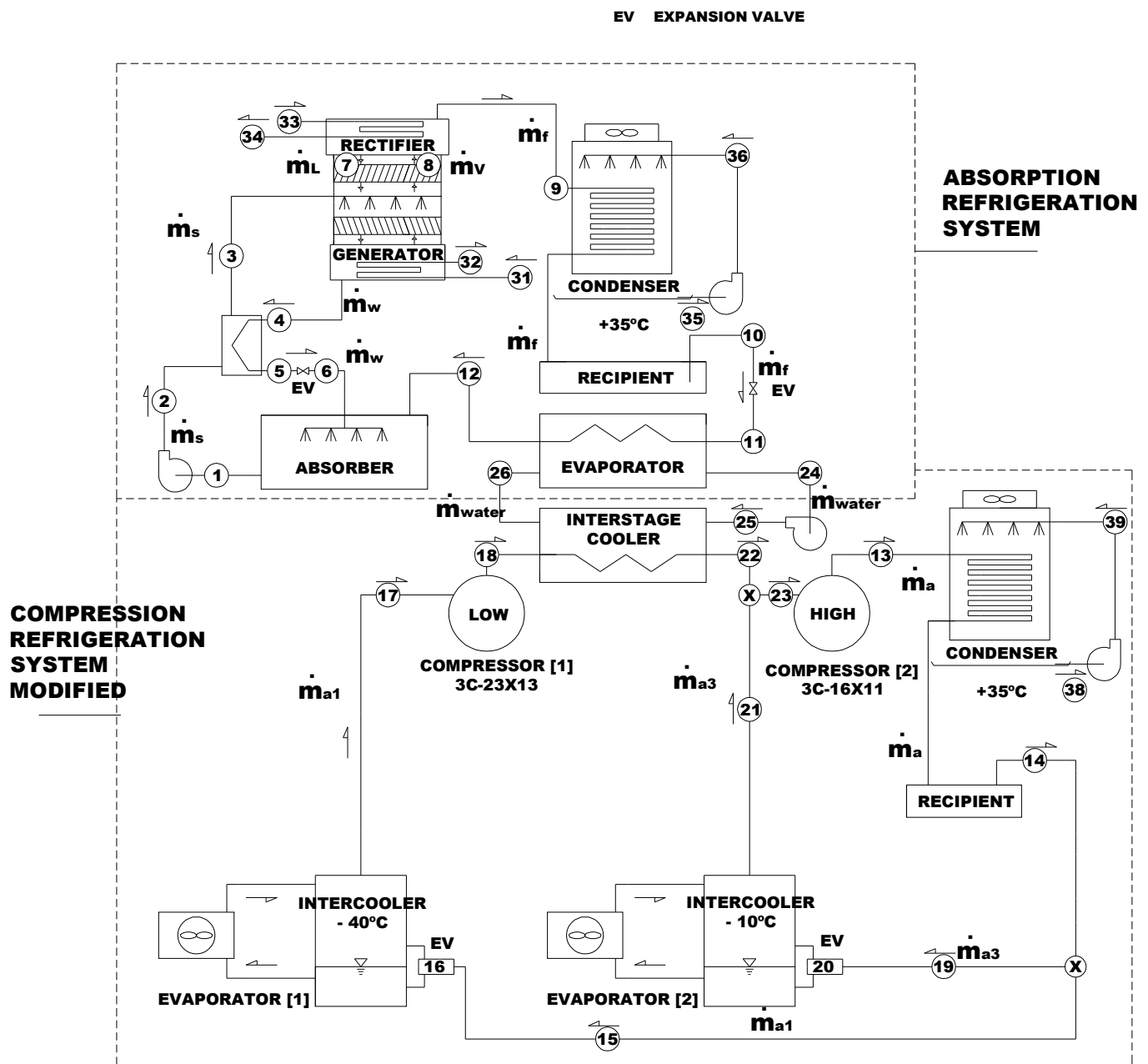

Figure 2. Schematic drawing of IRS.

Thermodynamic Considerations of the Conventional and Integrated Refrigerating Systems

The mathematical models applied in the simulation of the systems under study were obtained dividing the systems considered (Figs. 1 and 2) in the thermodynamic analysis, in various control volumes and applying to these the balance of mass, energy and exergy. In this analysis, the following considerations are made:

- The components of the systems are analyzed in a permanent regime.

- The effects of variation of kinetic energy and potential are not taken into account.

- Expansion through the valves is a throttle process.

- The working fluid is saturated liquid in the exit of condensers, saturated vapor in the entrance of the compressor of low and overheated vapor at $7^{\circ}$ $\mathrm{C}$ in the compressor of high pressure

- Room temperature and pressure for the calculation of exergy are respectively $T_{0}=293 \mathrm{~K}$ and $\mathrm{p}_{0}=1 \mathrm{bar}$.
- In ARS the temperatures in the condenser, evaporator, absorber, generator and rectifier are constant and uniform along the components.

- Pressures in the condenser and evaporator of ARS are balance pressures corresponding to the temperatures and concentrations of the condenser and evaporator respectively.

- The strong solution $\mathrm{x}_{\mathrm{s}}$ in the exit of absorber and the weak solution $x_{w}$ in the exit of the generator are balanced with their respective temperatures and pressures.

- The concentration of refrigerant vapor in the exit of the rectifier is equal to $\mathrm{x}_{\mathrm{f}}=0.999$

The regime of work in the frigorific plant was obtained through instrumentation, during the operation of the system. Such data are presented in Table 1 and will be a source for the following guidelines of calculation for CRS and IRS:

In Table 1, the refrigerant fluid in each cluster $(14,15,19$ e 24$)$ and (20 e 25), presented the same state, pressure and temperature, but with different mass flow rates.

To the regime of work in the frigorific plant modified CRSmod, it was admitted the same as in 
CRS, but there are not the positions 24 and 25 by not occurring an injection of liquid between the stages of high and low.

Table 2 presents the operational data of the absorption refrigeration system (ARS). The temperatures of the solutions are determined numerically.

Table 1 - Data for CRS

Power input for the low-pressure compressor: $32.95 \mathrm{~kW}$ Power input for the high-pressure compressor : $61.23 \mathrm{~kW}$ Ambient temperature: $25^{\circ} \mathrm{C}$

Ambiente pressure: $101 \mathrm{kPa}$

$\mathrm{T}_{\text {in }}$ and $\mathrm{T}_{\text {out }}$ cooling water: $25^{\circ} \mathrm{C}$ and $30^{\circ} \mathrm{C}$

Refrigerant: NH3

\begin{tabular}{|c|c|c|c|}
\hline Point & Fluid state & $\mathbf{T}\left[{ }^{\mathbf{0}} \mathbf{C}\right]$ & $\mathbf{P}[\mathbf{k P a}]$ \\
\hline 13 & overheated vapour & 112,5 & 1351 \\
\hline $14,15,19,24$ & Saturated liquid & 35 & 1351 \\
\hline 16 & Liquid + vapour & -40 & 71.66 \\
\hline 17 & Saturated vapour & -40 & 71.66 \\
\hline 18 & overheated vapour & 48.9 & 290.8 \\
\hline 20,25 & Liquid + vapour & -10 & 290.8 \\
\hline 21 & Saturated vapour & -10 & 290.8 \\
\hline 23 & overheated vapour & 7 & 290.8 \\
\hline \multicolumn{4}{|l}{}
\end{tabular}

This installation presents data with the following considerations:

1- The frigorific capacity of ARS is the same as the heat removed from the intermediate cooler of CRSmod obtained by thermal balance of the latter.

2- They were attributed practical values for the range of the process, concentrations, temperatures and pressures applied and verified in COP which would meet the needs of the operation.

Table 2 - Data for IRS

$\dot{\mathrm{Q}}_{\text {resf }}$ Heat-transfer rate by the intercooler: $8.918 \mathrm{~kW}$

$\mathrm{T}_{0}$ Ambient temperature: $25^{\circ} \mathrm{C}$

$\mathrm{P}_{0}$ Ambient pressure: $101 \mathrm{kPa}$

$\mathrm{T}_{\text {in }}, \mathrm{T}_{\text {out }}$ (Fig.2) cooling water: $25^{\circ} \mathrm{C}$ and $30^{\circ} \mathrm{C}$

$\mathrm{T}_{\text {in }}, \mathrm{T}_{\text {out }}$ (Fig.2) heating water: $96^{\circ} \mathrm{C}$ and $90^{\circ} \mathrm{C}$

Fluid : NH3-H2O

$\Delta \mathrm{x}=$ strong solution - weak solution: 0.05

\begin{tabular}{|c|c|c|c|r|c|}
\hline Point & State & $\begin{array}{c}\mathbf{T} \\
{\left[{ }^{\mathbf{C}} \mathbf{C}\right]}\end{array}$ & $\mathbf{x ~}_{\mathbf{N H} 3} / \mathbf{g}_{\text {sol }}$ & $\begin{array}{c}\mathbf{P} \\
{[\mathbf{b a r}]}\end{array}$ & Solution \\
\hline 1 & Liquid & 45.0 & 0.45 & 4.60 & strong \\
\hline 2 & Liquid & 45.0 & 0.45 & 11.62 & strong \\
\hline 3 & Liquid & 58.0 & 0.45 & 11.62 & strong \\
\hline 4 & Liquid & 88.0 & 0.40 & 11.62 & weak \\
\hline 5 & Liquid & 83.5 & 0.40 & 11.62 & weak \\
\hline 6 & Liq.+vap. & 61.7 & 0.40 & 4.60 & weak \\
\hline 7 & Liquid & 78.5 & 0.45 & 11.62 & - \\
\hline 8 & Vapour & 78.5 & 0.98 & 11.62 & - \\
\hline 9 & Vapour & 30.0 & 0.999 & 11.62 & solution \\
\hline 10 & Liquid & 30.0 & 0.999 & 11.62 & solution \\
\hline 11 & Liq.+vap. & 2.0 & 0.999 & 4.60 & solution \\
\hline 12 & Vapour & 2 & 0.999 & 4.602 & solution \\
\hline
\end{tabular}

Construction of energetic functions for CRS
The balance of mass and energy for each volume of control are presented, where the numeric rates represent the states of the working fluid in the cycle of Figure 1:

Condenser Unit - The condenser cools and condenses the overheated vapor coming from the compressor of high. This operation is carried out transferring the heat of the refrigerant fluid to the medium. Water is used as refrigerant fluid.

$$
\dot{\mathrm{Q}}_{\mathrm{C}}=\dot{\mathrm{m}}_{\mathrm{a}}\left(\mathrm{h}_{13}-\mathrm{h}_{14}\right)
$$

Evaporator Unit 1 - It is a heat exchanger where the evaporation of the refrigerant liquid takes place to the lowest pressure and temperature of the compression system.

$$
\dot{\mathrm{Q}}_{\mathrm{E} 1}=\dot{\mathrm{m}}_{\mathrm{a} 1}\left(\mathrm{~h}_{17}-\mathrm{h}_{16}\right)
$$

Evaporator Unit 2 - Evaporator 2 is responsible by the removal of heat, temperature and intermediate pressure of the compression system.

$$
\dot{\mathrm{Q}}_{\mathrm{E} 2}=\dot{\mathrm{m}}_{\mathrm{a} 3}\left(\mathrm{~h}_{21}-\mathrm{h}_{20}\right)
$$

Compressor Unit 1 - The amount of energy provided to the system in the time unit in compression represents the mechanic power of the first stage.

$$
\dot{\mathrm{W}}_{1}=\dot{\mathrm{m}}_{\mathrm{a} 1}\left(\mathrm{~h}_{18}-\mathrm{h}_{17}\right)
$$

The mechanic power required from the compressor 1 is obtained, using the specifications of the manufacturer for the compressor model applied (MADEF 3C-16x11), according to the procedure described by Pohlmann (1964), who makes the connection to the variance of power for different operational conditions for temperature and pressure.

Compressor Unit 2 - represents the mechanic power in the $2^{\text {nd }}$ stage.

$$
\dot{\mathrm{W}}_{2}=\dot{\mathrm{m}}_{\mathrm{a}}\left(\mathrm{h}_{13}-\mathrm{h}_{23}\right)
$$

Likewise, the mechanic power required by compressor 2 is obtained from the specifications of the manufacturer for the compressor model applied (MADEF 3C-23x13).

Mixtures - The refrigerant fluid compressed by the low pressure (state 18) is rarefied by injecting a liquid (state 25) resulting in state 22 . The fluid in this state is mixed with the vapor in state (21) and, by the end, in state (23) it is aspired by compressor 2 .

$$
\begin{gathered}
\dot{\mathrm{m}}_{\mathrm{a}}=\dot{\mathrm{m}}_{\mathrm{a} 1}+\dot{\mathrm{m}}_{\mathrm{a} 2}+\dot{\mathrm{m}}_{\mathrm{a} 3} \\
\left(\dot{\mathrm{m}}_{\mathrm{a} 1}+\dot{\mathrm{m}}_{\mathrm{a} 2}\right) \mathrm{h}_{22}=\dot{\mathrm{m}}_{\mathrm{a} 1} \mathrm{~h}_{18}+\dot{\mathrm{m}}_{\mathrm{a} 2} \mathrm{~h}_{25} \\
\dot{\mathrm{m}}_{\mathrm{a}} \mathrm{h}_{23}=\dot{\mathrm{m}}_{\mathrm{a} 3} \mathrm{~h}_{21}+\left(\dot{\mathrm{m}}_{\mathrm{a} 1}+\dot{\mathrm{m}}_{\mathrm{a} 2}\right) \mathrm{h}_{22}
\end{gathered}
$$

With the pressures of the condenser, evaporators and entrance and exit temperatures of the compressors, obtained through reading in the instrumentation existing in the frigorific plant, it is determined the following properties: temperatures of saturation, enthalpies, entropies and specific volumes. The mass flow rates $\dot{\mathrm{m}}_{\mathrm{a} 1}$ and $\dot{\mathrm{m}}_{\mathrm{a}}$ are 
determined with the equations (4) and (5). As to equations $(6,7$ and 8$)$ the mass flow rates $\dot{\mathrm{m}}_{\mathrm{a} 2}$ and $\dot{\mathrm{m}}_{\mathrm{a} 3}$ are determined, and the enthalpy $\mathrm{h}_{22}$. The rates of heat in the evaporators 1 and 2, respectively $\dot{\mathrm{Q}}_{\mathrm{E} 1}$ and $\dot{\mathrm{Q}}_{\mathrm{E} 2}$, and the heat rate in the condenser $\dot{\mathrm{Q}}_{\mathrm{C}}$ is obtained by equations (1, 2 and 3$)$, respectively.

The polytropic coefficient of the $1^{\text {st }}$ stage $\left(n_{1}\right)$ is obtained by Eq. (9) and about the condition obtained from the reading of pressures and temperatures obtained in the frigorific plant by the compressor 1. This polytropic coefficient, $\mathrm{n}_{1}$, is then considered constant for all the numeric simulations carried out in this work. An identical procedure is made for the calculation of the polytropic coefficient for the compressor in the $2^{\text {nd }}$ stage, $\mathrm{n}_{2}$ through eq. (10).

$$
\begin{gathered}
\frac{\mathrm{n}_{1}-1}{\mathrm{n}_{1}}=\frac{\log \frac{\mathrm{T}_{18}}{\mathrm{~T}_{17}}}{\log \frac{\mathrm{p}_{18}}{\mathrm{p}_{17}}} \\
\frac{\mathrm{n}_{2}-1}{\mathrm{n}_{2}}=\frac{\log \frac{\mathrm{T}_{13}}{\mathrm{~T}_{23}}}{\log \frac{\mathrm{p}_{13}}{\mathrm{p}_{23}}}
\end{gathered}
$$

In the numeric simulation of the compression refrigeration system (CRS), they are admitted for the working fluid different values for the inlet and outlet pressures for the compressors, as well as for the inlet temperatures in the compressors. The outlet temperatures of the compressors were obtained by equations ( 9 e 10), with the assumption that the polytrophic coefficients might be constant. With these pressures and temperatures, they are determined the other properties.

The coefficient of performance (COP) matches the frigorific capacity with the mechanical power provided to the system

$$
\mathrm{COP}_{\mathrm{CRS}}=\frac{\dot{\mathrm{Q}}_{\mathrm{E} 1}+\dot{\mathrm{Q}}_{\mathrm{E} 2}}{\dot{\mathrm{W}}_{1}+\dot{\mathrm{W}}_{2}}
$$

Figure 3 presents diagram $\mathrm{p}$-h of ammonia for CRS, where the characteristics of the refrigerating in any state are represented by the continuing lines.

In this diagram it can be observed that the inlet and outlet states of the refrigerant fluid ammonia, provided by readings (pressure and temperature) in the compressors of high pressure (states 23 and 13) and low pressure (states 17 and 18) installed in the frigorific plant.

\section{Construction of the energetic functions of IRS}

The methodology applied in the thermodynamic analysis of IRS allows to considerate the CRSmod and the ARS as two subsystems which, for a matter of simplicity, will be analyzed separately.

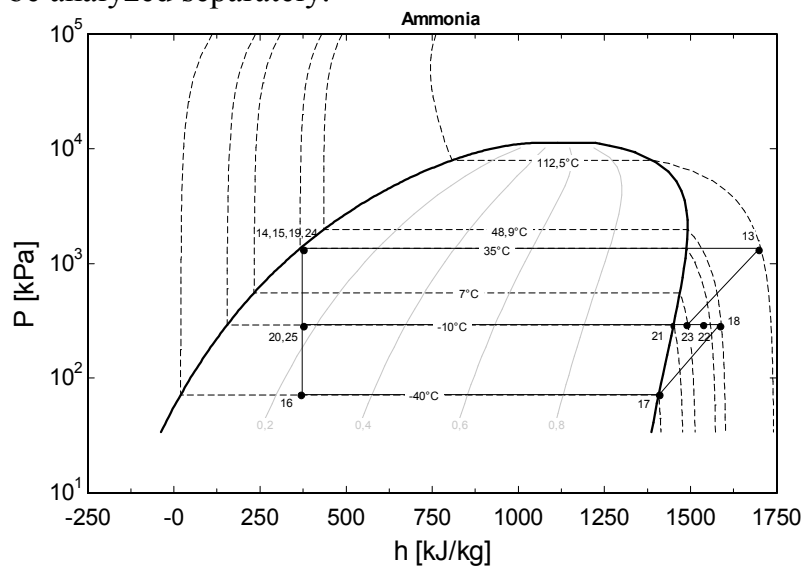

Figure 3. Diagram p-h: ammonia of CRS

\section{Energetic Functions of CRSmod}

As for CRS, eq. (1) - (5), (9) and (10) are valid under the assumptions mentioned in the previous section. For the mixture which is admitted in the compressor of high pressure we have: mixture

$$
\begin{gathered}
\dot{\mathrm{m}}_{\mathrm{a}}=\dot{\mathrm{m}}_{\mathrm{a} 1}+\dot{\mathrm{m}}_{\mathrm{a} 3} \\
\dot{\mathrm{m}}_{\mathrm{a}} \mathrm{h}_{23}=\dot{\mathrm{m}}_{\mathrm{a} 3} \mathrm{~h}_{21}+\dot{\mathrm{m}}_{\mathrm{a} 1} \mathrm{~h}_{22}
\end{gathered}
$$

unit - Cooler

$$
\dot{\mathrm{Q}}_{\text {resf. }}=\dot{\mathrm{m}}_{\mathrm{a} 1}\left(\mathrm{~h}_{18}-\mathrm{h}_{22}\right)
$$

With the pressures and temperatures of the working fluid in the entrance and exit of the compressors they are determined the properties: saturation temperatures, enthalpy and specific volumes.

Provided the mechanical powers and with the eq. (4) and (5) they are determined the flows $\dot{\mathrm{m}}_{\mathrm{a} 1}$ and $\dot{\mathrm{m}}_{\mathrm{a} 3}$, and with the eq. (12) and (13) the flow $\dot{\mathrm{m}}_{\mathrm{a}}$ and enthalpy $\mathrm{h}_{23}$ are determined. The heat changes of the evaporators (1) and (2), respectively $\dot{\mathrm{Q}}_{\mathrm{E} 1}$ and $\dot{\mathrm{Q}}_{\mathrm{E} 2}$, and the heat rates in the condenser $\dot{\mathrm{Q}}_{\mathrm{C}}$ are obtained by eq. (1-3).

Fig. 4 presents diagram p-h: ammonia of CRSmod

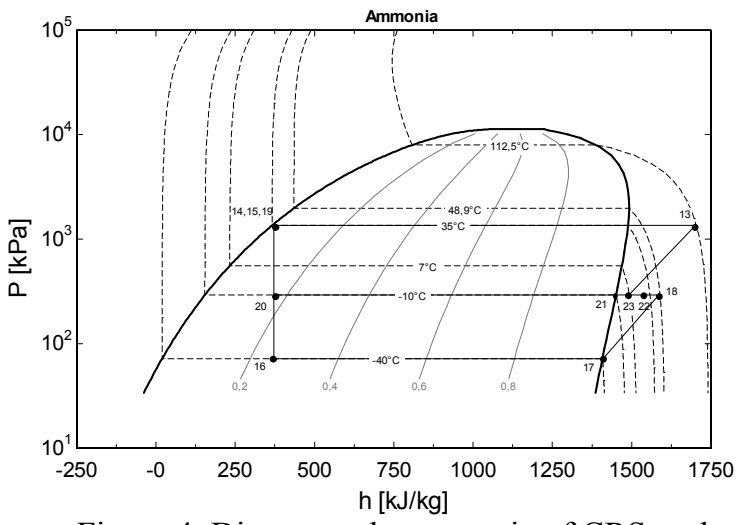

Figure 4. Diagram p-h: ammonia of CRSmod 


\section{Energetic Functions for SRA}

For the thermodynamic analysis of the absorption system are applied the principles of mass conservation, species and energy for each component of the system. Each component is treated such as a control volume with inlet and outlet of flows, and with interactions of heat and work transfer where: $\dot{m}$ is the mass flow rate of the solution ammonia-water, $\mathrm{x}$ is the concentration of mass of ammonia in the solution, and $h$ is the enthalpy of the solution ammonia-water, corresponding to the inlet and outlet state of each component. The sub index for the solution: "f" (fraction), "s" (strong), "w" (weak) "L"(liquid) and "V"(vapor) mean a species of concentration " $x$ " of the solution ammonia-water.

Unit - Condenser

$$
\dot{\mathrm{Q}}_{\mathrm{C}}=\dot{\mathrm{m}}_{\mathrm{f}}\left(\mathrm{h}_{9}-\mathrm{h}_{10}\right)
$$

Unit - Evaporator

$$
\begin{gathered}
\dot{\mathrm{Q}}_{\mathrm{E}}=\dot{\mathrm{Q}}_{\text {resf }} \\
\dot{\mathrm{Q}}_{\mathrm{E}}=\dot{\mathrm{m}}_{\mathrm{f}}\left(\mathrm{h}_{12}-\mathrm{h}_{11}\right)
\end{gathered}
$$

Unit - Absorber

$$
\begin{gathered}
\dot{\mathrm{m}}_{\mathrm{s}}=\dot{\mathrm{m}}_{\mathrm{w}}+\dot{\mathrm{m}}_{\mathrm{f}} \\
\dot{\mathrm{m}}_{\mathrm{s}} \mathrm{x}_{1}=\dot{\mathrm{m}}_{\mathrm{w}} \mathrm{x}_{6}+\dot{\mathrm{m}}_{\mathrm{f}} \mathrm{x}_{12} \\
\dot{\mathrm{Q}}_{\mathrm{a}}=\dot{\mathrm{m}}_{\mathrm{f}} \mathrm{h}_{12}+\dot{\mathrm{m}}_{\mathrm{w}} \mathrm{h}_{6}-\dot{\mathrm{m}}_{\mathrm{s}} \mathrm{h}_{1}
\end{gathered}
$$

Unit - Solution pump

$$
\begin{gathered}
\mathrm{h}_{2}=\mathrm{h}_{1}+\mathrm{v}_{1}\left(\mathrm{p}_{2}-\mathrm{p}_{1}\right) \\
\dot{\mathrm{W}}_{\mathrm{b}}=\dot{\mathrm{m}}_{\mathrm{s}}\left(\mathrm{h}_{2}-\mathrm{h}_{1}\right)
\end{gathered}
$$

Unit - Heat exchanger

$$
\begin{gathered}
\dot{\mathrm{m}}_{\mathrm{s}} \mathrm{x}_{2}+\dot{\mathrm{m}}_{\mathrm{w}} \mathrm{x}_{4}=\dot{\mathrm{m}}_{\mathrm{s}} \mathrm{x}_{3}+\dot{\mathrm{m}}_{\mathrm{w}} \mathrm{x}_{5} \\
\dot{\mathrm{m}}_{\mathrm{s}} \mathrm{h}_{2}+\dot{\mathrm{m}}_{\mathrm{w}} \mathrm{h}_{4}=\dot{\mathrm{m}}_{\mathrm{s}} \mathrm{h}_{3}+\dot{\mathrm{m}}_{\mathrm{w}} \mathrm{h}_{5}
\end{gathered}
$$

Unit - Generator

$$
\begin{gathered}
\dot{\mathrm{m}}_{\mathrm{s}}+\dot{\mathrm{m}}_{\mathrm{L}}=\dot{\mathrm{m}}_{\mathrm{w}}+\dot{\mathrm{m}}_{\mathrm{V}} \\
\dot{\mathrm{m}}_{\mathrm{s}} \mathrm{x}_{3}+\dot{\mathrm{m}}_{\mathrm{L}} \mathrm{x}_{7}=\dot{\mathrm{m}}_{\mathrm{w}} \mathrm{x}_{4}+\dot{\mathrm{m}}_{\mathrm{V}} \mathrm{x}_{8} \\
\dot{\mathrm{Q}}_{\mathrm{G}}=\dot{\mathrm{m}}_{\mathrm{w}} \mathrm{h}_{4}+\dot{\mathrm{m}}_{\mathrm{V}} \mathrm{h}_{8}-\dot{\mathrm{m}}_{\mathrm{s}} \mathrm{h}_{3}-\dot{\mathrm{m}}_{\mathrm{L}} \mathrm{h}_{7}
\end{gathered}
$$

Unit - Rectifier

$$
\begin{gathered}
\dot{\mathrm{m}}_{\mathrm{V}}=\dot{\mathrm{m}}_{\mathrm{L}}+\dot{\mathrm{m}}_{\mathrm{f}} \\
\dot{\mathrm{m}}_{\mathrm{V}} \mathrm{x}_{8}=\dot{\mathrm{m}}_{\mathrm{L}} \mathrm{x}_{7}+\dot{\mathrm{m}}_{\mathrm{f}} \mathrm{x}_{9} \\
\dot{\mathrm{Q}}_{\mathrm{R}}=\dot{\mathrm{m}}_{\mathrm{V}} \mathrm{h}_{8}-\dot{\mathrm{m}}_{\mathrm{l}} \mathrm{h}_{9}-\dot{\mathrm{m}}_{\mathrm{L}} \mathrm{h}_{7}
\end{gathered}
$$

Coefficient of performance of IRS

$$
\mathrm{COP}=\frac{\dot{\mathrm{Q}}_{\mathrm{E} 1}+\dot{\mathrm{Q}}_{\mathrm{E} 2}}{\dot{\mathrm{W}}_{1}+\dot{\mathrm{W}}_{2}+\dot{\mathrm{W}}_{\mathrm{b}}+\dot{\mathrm{Q}}_{\mathrm{G}}}
$$

\section{Construction of the exergetic functions of CRS}

The exergetic analysis is obtained by the combination of the first and second law of thermodynamic, where Kotas (1985) states that exergy is the standard of quality for energy, and it is equal to the maximum useful work which can be obtained by a given form of energy, using the environment $\left(\mathrm{P}_{0}, \mathrm{~T}_{0}\right)$ as reference.

The main connections to be made in the thermodynamic exergetic analysis of flow are the balance of mass and exergy in permanent regime, not taking into consideration the variation of kinetic and potential energy, and according to Bejan et al. (1996) the physical energy can be calculated in mass basis $\left(\mathrm{e}^{\mathrm{PH}}\right)$ as in:

$$
\mathrm{e}^{\mathrm{PH}}=\left(\mathrm{h}-\mathrm{h}_{0}\right)-\mathrm{T}_{0}\left(\mathrm{~s}-\mathrm{s}_{0}\right)
$$

Where $\mathrm{h}_{0}$ and $\mathrm{s}_{0}$ are properties assessed in temperature $\mathrm{T}_{0}$ and environmental pressure $\mathrm{P}_{0}$.

In this conception we have as a product the energy rates of the evaporators 1 and 2 , as fuel to the electric power provided to the compressors 1 and 2. As a loss is taken into consideration, the whole process of cool water consumption by CRS coming from an external environment.

Unit - Evaporator 1

$$
\dot{\mathrm{E}}_{17}-\dot{\mathrm{E}}_{16}=\dot{\mathrm{m}}_{\mathrm{a} 1}\left(\mathrm{e}_{17}-\mathrm{e}_{16}\right)
$$

Unit - Evaporator 2

$$
\dot{\mathrm{E}}_{21}-\dot{\mathrm{E}}_{20}=\dot{\mathrm{m}}_{\mathrm{a} 3}\left(\mathrm{e}_{21}-\mathrm{e}_{20}\right)
$$

Unit - Compressor $1^{\text {st }}$ stage

$$
\begin{gathered}
\dot{\mathrm{E}}_{18}-\dot{\mathrm{E}}_{17}=\dot{\mathrm{m}}_{\mathrm{a} 1}\left(\mathrm{e}_{18}-\mathrm{e}_{17}\right) \\
\dot{\mathrm{W}}_{1 \mathrm{e}}=\frac{\dot{\mathrm{m}}_{\mathrm{a} 1}\left(\mathrm{~h}_{18}-\mathrm{h}_{17}\right)}{\eta_{\mathrm{C}}}
\end{gathered}
$$

Unit - Compressor $2^{\text {nd }}$ stage

$$
\begin{gathered}
\dot{\mathrm{E}}_{13}-\dot{\mathrm{E}}_{23}=\dot{\mathrm{m}}_{\mathrm{a}}\left(\mathrm{e}_{13}-\mathrm{e}_{23}\right) \\
\dot{\mathrm{W}}_{2 \mathrm{e}}=\frac{\dot{\mathrm{m}}_{\mathrm{a}}\left(\mathrm{h}_{13}-\mathrm{h}_{23}\right)}{\eta_{\mathrm{C}}}
\end{gathered}
$$

Where $\dot{\mathrm{W}}_{1 \mathrm{e}}$ and $\dot{\mathrm{W}}_{2 \mathrm{e}}$ are the electric powers provided to the mechanic compressors of the $1^{\text {st }}$ and $2^{\text {nd }}$ stage, and the mean average performance $\left(\eta_{C}=0.504\right)$ corresponds to the product of thermal performance $\left(\eta_{\mathrm{t}}=0.7\right)$, mechanic $\left(\eta_{\mathrm{m}}=0.8\right)$ and electric $\left(\eta_{\mathrm{e}}=0.9\right)$.

In order to simplify the simulation and analysis of heat transfer among the system and its environments, the contribution of the work in water pump and the losses by friction in the system were neglected. Thus, the exergetic efficiency $\varepsilon$ which is the correlation between the product and the fuel summarizes itself. (Fig. 1):

$$
\varepsilon_{\mathrm{CRS}}=\frac{\left(\dot{\mathrm{E}}_{17}-\dot{\mathrm{E}}_{16}\right)+\left(\dot{\mathrm{E}}_{21}-\dot{\mathrm{E}}_{20}\right)}{\dot{\mathrm{W}}_{1 \mathrm{e}}+\dot{\mathrm{W}}_{2 \mathrm{e}}}
$$

\section{Construction of the exergetic functions IRS}

In the exergetic analysis they were applied the balance of mass and exergy in permanent regime, not taking into account the variation of kinetic and power energy. 
In this conception, we have as a product the energy rates of the evaporators 1 and 2, as fuel: the electric power provided to the compressors, the electric power provided to the pump, the solution ammonia-water, the energy rate provided to the generators. As the loss, the process of cold water consumption of IRS coming from the exterior medium is taken into account.

Construction of the exergetic functions of CRSmod

Unit - Evaporator 1

$$
\dot{\mathrm{E}}_{17}-\dot{\mathrm{E}}_{16}=\dot{\mathrm{m}}_{\mathrm{a} 1}\left(\mathrm{e}_{17}-\mathrm{e}_{16}\right)
$$

Unit - Evaporator 2

$$
\dot{\mathrm{E}}_{21}-\dot{\mathrm{E}}_{20}=\dot{\mathrm{m}}_{\mathrm{a} 3}\left(\mathrm{e}_{21}-\mathrm{e}_{20}\right)
$$

Unit - Compressor $1^{\text {st }}$ stage

$$
\dot{\mathrm{W}}_{\mathrm{le}}=\frac{\dot{\mathrm{m}}_{\mathrm{a} 1}\left(\mathrm{~h}_{18}-\mathrm{h}_{17}\right)}{\eta_{\mathrm{C}}}
$$

Unit - Compressor $2^{\text {nd }}$ stage

$$
\dot{\mathrm{W}}_{2 \mathrm{e}}=\frac{\dot{\mathrm{m}}_{\mathrm{a}}\left(\mathrm{h}_{13}-\mathrm{h}_{23}\right)}{\eta_{\mathrm{C}}}
$$

\section{Construction of the exergetic function of ARS}

The total exergy, E, of a refrigeration system by absorption according to Misra et al. (2006) is the addition of physical exergy, $\mathrm{E}^{\mathrm{PH}}$, and the exergy of chemical substance $\mathrm{E}^{\mathrm{CH}}$, as well as the specific total exergy is the addition of specific total exergy, $\mathrm{e}^{\mathrm{ph}}$, and exergy of specific chemical exergy, $\mathrm{e}^{\mathrm{ch}}$.

The procedure of calculation of specific chemical exergy of the mixture for the system ammonia-water according to Misra et al. (2006) is calculated by

$$
e^{\mathrm{CH}}=\left(\frac{\mathrm{x}}{\mathrm{M}_{\mathrm{NH}_{3}}}\right) \mathrm{e}_{\mathrm{ch}, \mathrm{NH}_{3}}^{0}+\left(\frac{1-\mathrm{x}}{\mathrm{M}_{\mathrm{H}_{2} \mathrm{O}}}\right) \mathrm{e}_{\mathrm{ch}, \mathrm{H}_{2} \mathrm{O}}^{0}
$$

The specific chemical exergy of ammonia $\mathrm{e}_{\mathrm{ch}, \mathrm{NH}_{3}}^{0}$ and of water $\mathrm{e}_{\mathrm{ch}, \mathrm{H}_{2} \mathrm{O}}^{0}$ were obtained in Bejan et al. (1996).

Unit - Pump of the solution ammonia-water

$$
\dot{\mathrm{Wb}}_{\mathrm{e}}=\frac{\dot{\mathrm{m}}_{\mathrm{s}}\left(\mathrm{h}_{2}-\mathrm{h}_{1}\right)}{\eta_{\mathrm{b}}}
$$

The performance of the pump $\left(\eta_{b}\right)$ is worth 0.5

Unit - Generator

$$
\begin{gathered}
\dot{\mathrm{E}}_{30}-\dot{\mathrm{E}}_{31}=\dot{\mathrm{m}}_{\text {vapor }}\left(\mathrm{e}_{30}-\mathrm{e}_{31}\right) \\
\dot{\mathrm{E}}_{30}-\dot{\mathrm{E}}_{31}=\dot{\mathrm{m}}_{\mathrm{s}} \mathrm{e}_{\mathrm{x} 3}+\dot{\mathrm{m}}_{\mathrm{L}} \mathrm{e}_{\mathrm{x} 7}-\dot{\mathrm{m}}_{\mathrm{w}} \mathrm{e}_{\mathrm{x} 4}-\dot{\mathrm{m}}_{\mathrm{V}} \mathrm{e}_{\mathrm{x} 8}
\end{gathered}
$$

The exergetic performance $\varepsilon$ of IRS:

$$
\varepsilon_{\mathrm{SRI}}=\frac{\left(\dot{\mathrm{E}}_{17}-\dot{\mathrm{E}}_{16}\right)+\left(\dot{\mathrm{E}}_{21}-\dot{\mathrm{E}}_{20}\right)}{\dot{\mathrm{W}}_{1 \mathrm{e}}+\dot{\mathrm{W}}_{2 \mathrm{e}}+\dot{\mathrm{Wb}}_{\mathrm{e}}+\left(\dot{\mathrm{E}}_{30}-\dot{\mathrm{E}}_{31}\right)}
$$

Where $\left(E_{30}-E_{31}\right)$ is the heat provided (fuel) to the ARS in the generator.

\section{RESULTS AND DISCUSSION}

Table 3 shows for each state, the values " $\dot{\mathrm{m}}$, $h$, and $\mathrm{e}$ " in each position of interest of CRS, in the operational conditions shown in Fig. 1. The pressures and temperatures corresponding to the states shown in Tables 3 and 5, are found respectively in Tables 1 and 2 .

Table 3 - State-point properties of $\mathrm{NH}_{3}$ and mass flow rate of CRS

\begin{tabular}{|c|c|c|c|}
\hline State & $\mathbf{h}[\mathbf{k J} / \mathbf{k g}]$ & $\dot{\mathrm{m}}[\mathbf{k g} / \mathbf{s}]$ & $\mathbf{e}[\mathbf{k J} / \mathbf{k g}]$ \\
\hline 13 & 1704 & 0.1459 & 864.3 \\
\hline 14 & 366 & 0.1459 & 798.7 \\
\hline 15 & 366 & 0.09134 & 798.7 \\
\hline 16 & 366 & 0.09134 & 736.7 \\
\hline 17 & 1408 & 0.09134 & 446.9 \\
\hline 18 & 1589 & 0.09134 & 631.3 \\
\hline 19 & 366 & 0.04849 & 798.7 \\
\hline 20 & 366 & 0.04849 & 778.3 \\
\hline 21 & 1450 & 0.04849 & 634.7 \\
\hline 22 & 1514 & 0.09738 & 629.6 \\
\hline 23 & 1493 & 0.1459 & 630.6 \\
\hline
\end{tabular}

Table 4 shows the results of the energetic and exergetic balances, of (COP) and exergetic efficiency $(\varepsilon)$ of CRS.

Table 4 - Results of the thermodynamic balances, of COP and $\varepsilon$ of CRS

\begin{tabular}{|c|c|c|c|c|}
\hline \multicolumn{3}{|c|}{ Energetic } & \multicolumn{2}{c|}{ Exergetic } \\
\hline$\dot{\mathrm{Q}}_{\mathrm{E} 1}$ & $\dot{\mathrm{Q}}_{\mathrm{E} 2}$ & $\dot{\mathrm{Q}}_{\mathrm{C}}$ & $\Delta \dot{\mathrm{E}}_{\mathrm{E} 1}$ & $\Delta \dot{\mathrm{E}}_{\mathrm{E} 2}$ \\
{$[\mathbf{k W}]$} & {$[\mathbf{k W}]$} & {$[\mathbf{k W}]$} & {$[\mathbf{k W}]$} & {$[\mathbf{k W}]$} \\
\hline 95.15 & 52.57 & 195.2 & 26.47 & 6.96 \\
\hline$\dot{\mathrm{W}}_{1}$ & $\dot{\mathrm{W}}_{2}$ & $\mathrm{COP}_{\mathrm{CRS}}$ & $\dot{\mathrm{W}}_{1 \mathrm{e}}$ & $\dot{\mathrm{W}}_{2 \mathrm{e}}$ \\
{$[\mathbf{k W}]$} & {$[\mathbf{k W}]$} & & {$[\mathbf{k W}]$} & {$[\mathbf{k W}]$} \\
\hline 16.61 & 30.86 & 3.112 & 32.95 & 61.23 \\
\hline \multicolumn{4}{|c|}{$\varepsilon_{\mathrm{CRS}}=0.355$} \\
\hline
\end{tabular}

Table 5 shows the properties of state and mass flow of IRS.

Comparing the results of Tables 3 and 4, obtained both for the same operational conditions $\left(\mathrm{T}_{\mathrm{E} 1}=-40^{\circ} \mathrm{C}, \mathrm{T}_{\mathrm{E} 2}=-10^{\circ} \mathrm{C}\right.$ and $\left.\mathrm{T}_{\mathrm{C}}=35^{\circ} \mathrm{C}\right)$ it is observed that for IRS values lower than $19.37 \%$ in COP regarding to CRS. However, in the efficiency ( $\varepsilon$ ) IRS presented an increase of $25.57 \%$ regarding to CRS. This increase in the efficiency is due to an increase in the exergetic frigorific capacity $\left(\Delta \mathrm{E}_{\mathrm{E} 1}+\Delta \mathrm{E}_{\mathrm{E} 2}\right)$ of $33.09 \%$ regarding to $\mathrm{CRS}$, which accounts for applying IRS.

Through the simulation of several operational conditions it was investigated the influence of the temperatures in obtaining exchanged heat of the components, power of compressors, performance (COP) and efficiency $(\varepsilon)$ of the facilities. All of these results were presented in graphs. 
Table 5 - State-point properties and mass flow rate of IRS

\begin{tabular}{|c|c|c|c|}
\hline \multicolumn{4}{|c|}{ Mixture: $\mathrm{NH}_{3}+\mathrm{H}_{2} \mathrm{O}$} \\
\hline state & $\begin{array}{c}\mathbf{h} \\
{[\mathbf{k J} / \mathbf{k g}]}\end{array}$ & $\begin{array}{c}\dot{\mathrm{m}} \\
{[\mathbf{k g} / \mathbf{s}]}\end{array}$ & $\begin{array}{c}\mathbf{e} \\
{[\mathbf{k J} / \mathbf{k g}]}\end{array}$ \\
\hline 1 & -40.54 & 0.0477 & -4.651 \\
\hline 2 & -15.7 & 0.0477 & -1.354 \\
\hline 3 & 42.51 & 0.0477 & 4.13 \\
\hline 4 & 355.2 & 0.03916 & 70.4 \\
\hline 5 & 284.3 & 0.03916 & 53.47 \\
\hline 6 & 284.3 & 0.03916 & 45.47 \\
\hline 7 & 297.7 & 0.0009108 & 52.16 \\
\hline 8 & 1561 & 0.009454 & 313.3 \\
\hline 9 & 1293 & 0.008543 & 268 \\
\hline 10 & 225.4 & 0.008543 & 194 \\
\hline 11 & 225.4 & 0.008543 & 59.85 \\
\hline 12 & 1269 & 0.008543 & 88.02 \\
\hline \multicolumn{4}{|c|}{ Fluid: $\mathrm{NH}_{3}$} \\
\hline state & $\mathbf{h}$ & $\dot{\mathrm{m}}$ & $\mathbf{e}$ \\
\hline $\mathbf{k J J} / \mathbf{k g}]$ & {$[\mathbf{k g} / \mathbf{s}]$} & {$[\mathbf{k J} / \mathbf{k g}]$} \\
\hline 13 & 1672 & 0.1893 & 857.6 \\
\hline 14 & 366 & 0.1893 & 798.7 \\
\hline 15 & 366 & 0.1216 & 798.7 \\
\hline 16 & 366 & 0.1216 & 736.7 \\
\hline 17 & 1408 & 0.1216 & 446.9 \\
\hline 18 & 1589 & 0.1216 & 631.3 \\
\hline 19 & 366 & 0.06775 & 798.7 \\
\hline 20 & 366 & 0.06775 & 778.3 \\
\hline 21 & 1450 & 0.06775 & 634.7 \\
\hline 22 & 1516 & 0.1216 & 629.5 \\
\hline 23 & 1493 & 0.1893 & 630.6 \\
\hline \multicolumn{4}{|c}{} \\
\hline
\end{tabular}

Table 6 shows the results of the energetic and exergetic balances, of (COP) and efficiency of IRS.

Table 6 - Results of the thermodynamic balances, of COP and $\varepsilon$ of IRS

\begin{tabular}{|c|c|c|}
\hline \multicolumn{3}{|c|}{ Energetic } \\
\hline$\dot{\mathrm{Q}}_{\text {Resf. }}[\mathrm{kW}]$ & $\dot{\mathrm{Q}}_{\mathrm{G}}[\mathrm{kW}]$ & $\dot{\mathrm{Q}}_{\mathrm{Ca}}[\mathrm{kW}]$ \\
\hline 8.918 & 26.37 & 9.119 \\
\hline$\dot{\mathrm{Q}}_{\mathrm{R}}[\mathrm{kW}]$ & $\dot{\mathrm{Q}}_{\mathrm{A}}[\mathrm{kW}]$ & $\dot{\mathrm{Wb}}[\mathrm{kW}]$ \\
\hline 3.443 & 23.91 & 1.185 \\
\hline$\dot{\mathrm{Q}}_{\mathrm{E} 1}[\mathrm{~kW}]$ & $\dot{\mathrm{Q}}_{\mathrm{E} 2}[\mathrm{~kW}]$ & $\dot{\mathrm{Q}}_{\mathrm{C}}[\mathrm{kW}]$ \\
\hline 126.6 & 73.45 & 437.8 \\
\hline$\dot{\mathrm{W}}_{1}[\mathrm{~kW}]$ & $\dot{\mathrm{W}}_{2}[\mathrm{~kW}]$ & $\mathrm{COP}_{\text {IRS }}$ \\
\hline 22.1 & 34.07 & 2.39 \\
\hline \multicolumn{3}{|c|}{ Exergetic } \\
\hline$\Delta \mathrm{E}_{\mathrm{E} 1}[\mathrm{~kW}]$ & $\Delta \mathrm{E}_{\mathrm{E} 1}[\mathrm{~kW}]$ & $\Delta \mathrm{E}_{\mathrm{E} 1}[\mathrm{~kW}]$ \\
\hline 35.23 & 35.23 & 35.23 \\
\hline$\dot{\mathrm{W}}_{1 \mathrm{e}}[\mathrm{kW}]$ & $\dot{\mathrm{W}}_{1 \mathrm{e}}[\mathrm{kW}]$ & $\dot{\mathrm{W}}_{1 \mathrm{e}}[\mathrm{kW}]$ \\
\hline 32.95 & 32.95 & 32.95 \\
\hline \multicolumn{3}{|c|}{$\varepsilon_{\text {IRS }}=0.4458$} \\
\hline
\end{tabular}

Figure 5, for CRS and IRS, presents the variation of refrigerating capacities and the power of compressors in function of temperature $\mathrm{T}_{\mathrm{E} 1}$ of the refrigerating fluid.
It is observed that as the temperature varies $\left(\mathrm{T}_{\mathrm{E} 1}\right)$, it results, for CRS as well as for IRS, in the same tendencies of variation of heat rates, and compressor powers. Still in this comparison, it can be observed a meaningful difference in the total heat rate of evaporators, $\dot{\mathrm{Q}}_{\mathrm{E}}$, of IRS of $33 \%$ higher than the correlation to the CRS. In this simulation, IRS presented a higher movimentation of mass flow rate in its components regarding to CRS, thus, higher heat rates. Another factor observed in Fig.5 is the total heat rate $\dot{\mathrm{Q}}_{\mathrm{E}}$, which remained constant during the rise of temperature $\mathrm{T}_{\mathrm{E} 1}$, while it occurred a reduction of $\dot{\mathrm{Q}}_{\mathrm{E} 2}$, due to the decrease of mass flow rate $\dot{\mathrm{m}}_{21}$ and increase of $\dot{\mathrm{Q}}_{\mathrm{E} 1}$. The powers $\dot{\mathrm{W}}_{1}$ and $\dot{\mathrm{W}}_{2}$, of IRS presented a higher percentage on average of $21.45 \%$ and $9.37 \%$ respectively regarding to the powers of CRS.

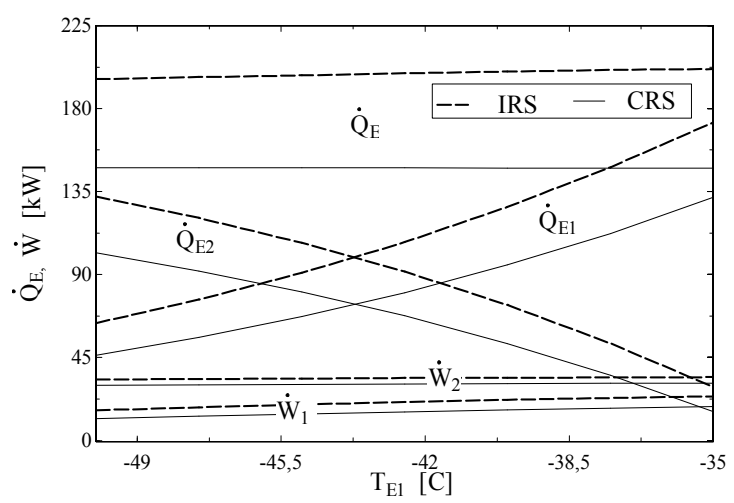

Figure 5. Variation of refrigerating capacity and power indicated in the compressors with $T_{E 1}$

Fig. 6 shows the variation of performance (COP) and efficiency $(\varepsilon)$ in terms of: condensation temperature, $\mathrm{T}_{\mathrm{C}}$, (Fig. 6-a); suction temperature of the $2^{\text {nd }}$ stage, $\mathrm{T}_{\text {SUCTION }}$ (Fig. 6-b); temperature of the evaporator $1, \mathrm{~T}_{\mathrm{E} 1}$ (Fig. 6-c) and the evaporator 2, $\mathrm{T}_{\mathrm{E} 2}$ (Fig. 6-d).

In Fig. 6-a, it is observed that the increase of $\mathrm{T}_{\mathrm{C}}$ reduced the performance, and the efficiency of the two systems analyzed. This is due to an increase in the mechanic power of the compressors and the reduction for the heat rate removed from the evaporators. It is also noted that the lower values of performance for $\mathrm{COP}_{\mathrm{IRS}}<\mathrm{COP}_{\mathrm{CRS}}$, where IRS had an average percentage of $26.62 \%$ lower regarding to $\mathrm{CRS}$, and higher values of efficiency $\left(\varepsilon_{\text {IRS }}>\varepsilon_{\text {CRS }}\right.$ ), where IRS presented a higher percentage on average of $26.02 \%$ regarding to CRS, owing to the product (frigorific capacity) presenting higher results in the exergetic analysis of IRS. 
(a)

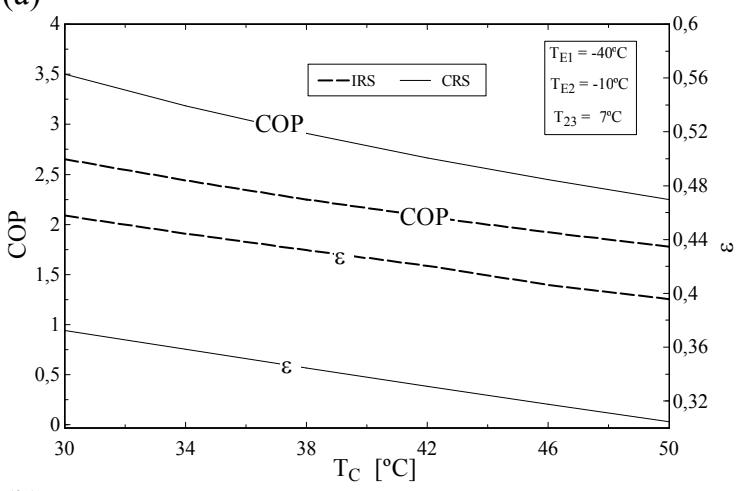

(b)

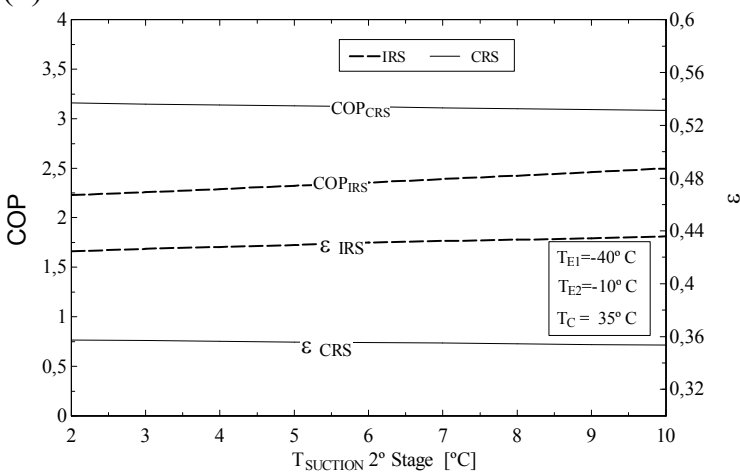

(c)

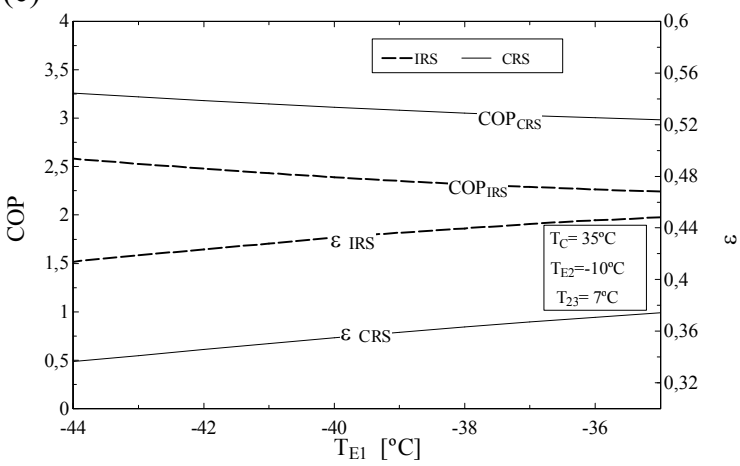

(d)

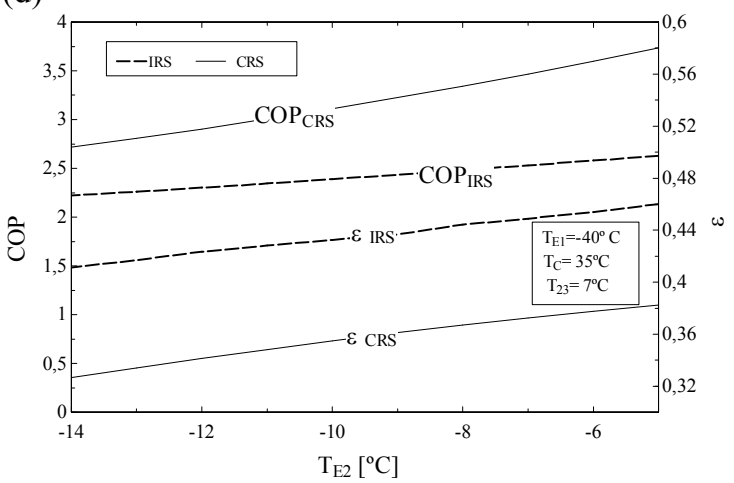

Figure 6- Variation of the performance (COP) and efficiency $(\varepsilon)$ in terms of: (a) condensation temperature, $T_{C}$, (b) suction temperature of the $2^{\text {nd }}$ stage, $\mathrm{T}_{\text {SUCTION }}$ (c) temperature of the evaporator $1, \mathrm{~T}_{\mathrm{E} 1},(\mathrm{~d})$ and the evaporator $2, \mathrm{~T}_{\mathrm{E} 2}$.

In Fig. 6-b, it is noticed that the increase of $\mathrm{T}_{\text {SUCTION }}$ reduces the performance and the efficiency of CRS, while for the IRS it raises the performance and efficiency. This increase in the IRS is due to a reduction in the heat rate of the generator $\dot{\mathrm{Q}}_{\mathrm{G}}$. For the increase of $\mathrm{T}_{\mathrm{SUCTION}}$ of compressor 2, it is decreased the intermediary cooling kept by the absorption system, that is, it was reduced the heat rate in generator $\dot{\mathrm{Q}}_{\mathrm{G}}$.

Fig. 6-c, shows a reduction of COP for systems CRS and IRS and an increase of efficiencies $\varepsilon_{\mathrm{CRS}}$ and $\varepsilon_{\mathrm{IRS}}$, as it increases $\mathrm{T}_{\mathrm{E} 1}$ of the evaporator 1 , maintaining $\mathrm{T}_{\mathrm{E} 2}=-10^{\circ} \mathrm{C}$. For the two systems CRS and IRS, the power of the compressors and the heat exchanged by the evaporators of the two systems increase, and as the relative increase of the compressors is larger it occurs a reduction in COP. As for the efficiencies, they increase due to an increase of the product (frigorific capacity) obtained of the exergetic balance.

Fig. 6-d, shows that as $\mathrm{T}_{\mathrm{E} 2}$ of evaporator 2 increases there is a rise of COP and efficiency $\varepsilon_{\text {CRS }}$ and $\varepsilon_{\text {IRS }}$ of the systems CRS and IRS. In these two systems the power of the compressors and the total heat rate of the evaporators rise, but in order to raise the value of COP. The efficiencies of both the systems rise owing to the growth of the product (frigorific capacity) obtained from the exergetic balance, even occurring a raise in the heat rate of the generator $\dot{\mathrm{Q}}_{\mathrm{G}}$ in IRS.

\section{CONCLUSION}

In this work it was shown an energetic and exergetic thermodynamic analysis of a refrigeration system by vapor compression (CRS) and of an integrated refrigeration system (IRS).

It was carried out a comparison between the two systems, where as a highlight the IRS presented efficiency $25.7 \%$ higher in relation to CRS. This increase in efficiency is due to the increase in the exergetic frigorific capacity $\left(\left(\Delta \mathrm{E}_{\mathrm{E} 1}+\Delta \mathrm{E}_{\mathrm{E} 2}\right)\right)$ of $33.09 \%$ regarding to CRS.

By the simulation of several operational conditions it was investigated the influence of the temperatures in obtaining the heat exchanged of the components, power of the compressors, performance (COP) and efficiency $(\varepsilon)$ of the installations, where the results proved that for IRS the values of COP are lower than those of CRS. However, the exergetic efficiency of the system IRS remained higher than in the system CRS.

IRS had in the energetic analysis an increase in the frigorific capacity of $35.42 \%$ regarding to the conventional system. This further advantage in which the thermal energy provided is of low cost makes the IRS more attractive. 
These results are very important in the context of thermodynamic optimization and of termoeconomic assessment of the refrigerating systems, where the lower operational cost which will be quantified in a future study, makes it worth the application of the integrated refrigeration system.

\section{REFERENCES}

Ashrae Handbook, 1994, System Practices for Ammonia Refrigerant, ASHRAE Refrigeration System and Applications, Atlanta, Ga.

Bejan, A., 1996, Entropy Generation Minimization, CRC Press, New York.

Bejan, A., Tsatsaronis G. and Moran M., 1996, Thermal design and optimization, Wiley, New York.

Bejan, A., 1988, Advanced Engineering Thermodynamics, Wiley, New York.

Cabello, R., Navarro-Esbrí, J., Lopis, R. and Torrilla, E., 2007, Analysis of the variation mechanism in the main energetic parameters in a single-stage vapour compression plant, Applied Thermal Engineering, Vol. 27, pp. $167-176$.

Göktun, S., 1999, Optimal performance of an irreversible, heat engine-driven, combined vapor compression and absorption refrigerator, Applied Energy, Vol. 62, pp. $67-79$.

Kairouani, L. and Nehdi, E., 2006, Cooling performance and energy saving of a compressionabsorption refrigeration system assisted by geothermal energy, Applied Thermal Engineering, Vol. 26, pp. $288-294$.

Kaynakli, O. and Kilic, M., 2007, Theoretical study on the effect of operating conditions on performance of absorption refrigeration system, Energy Conversion and Management, Vol. 48, No. 2, pp. $599-607$.

Kotas, T. J., 1985, The exergy method of thermal plant analysis. Great Britain: Anchor Brendon Ltd.

Misra, R. D., Sahoob, P. K. and Guptab, A., 2006, Thermoeconomic evaluation and optimization of an aqua-ammonia vapourabsorption refrigeration system, International Journal of Refrigeration, Vol.29, pp. $47-59$.

Nikolaids, C. and Probert, D., 1998, Exergymethod analysis of a two-stage vapour-compression refrigeration-plants performance, Applied Energy, Vol. 60, pp. $241-256$.

Pátek, J. and Komflar, J., 1995, Simple functions for fast calculations of selected thermodynamic properties of the ammonia-water system, International Journal of Refrigeration, Vol. 18 , No. 4, pp. 228-234.

Pohlmann, W., 1969, Manual de Tecnica Frigorifica. Edições Omega, S.A., Barcelona. 